\title{
Culture in vitro de la renoncule des fleuristes (Ranunculus asiaticus L). II. Production de plantes par culture d'anthères in vitro
}

\author{
J Meynet ${ }^{*}$, A Duclos \\ INRA, station d'amélioration des plantes florales, La Gaudine, Fréjus, 83370 Saint-Aygulf, France
}

(Reçu le 5 septembre 1989 ; accepté le 7 janvier 1990)

\begin{abstract}
Résumé - Des plantes viables sont obtenues par culture in vitro d'anthères de renoncules. Elles proviennent, soit de tissus superficiels. par embryogenèse somatique $(\mathrm{Em})$, soit des tissus internes par régénération de cals (C). Le génotype du donneur détermine presque toujours l'origine tissulaire des explants de façon exclusive. Cependant dans un cas (H1095) la présence de 2,4-D permet l'émergence conjointe des 2 types d'explants Em et C, alors qu'en l'absence de 2,4-D seuls les types $C$ sont produits. Un passage des anthères à $28^{\circ} \mathrm{C}$ et à l'obscurité pendant les 14 premiers jours de leur culture augmente significativement le rendement des embryons. L'obscurité en début de culture a très probablement un effet positif sur les taux d'embryogenèse et de callogenèse.
\end{abstract}

Ranunculus asiaticus / culture in vitro / anthère / embryon

Summary - In vitro culture of Persian Buttercup (Ranunculus asiaticus L) II. Production of plants through in vitro anther culture. Plants are obtained through in vitro culture of anthers in Ranunculus. They arise either from superficial tissues by somatic embryogenesis (Em), or from internal tissues by callus regeneration (C). The donor genotype is nearly always the cause of the tissular origin of the explant; however, in 1 case the presence of 2,4-D allowed the conjoined emergence of both Em and $C$ explant types while without 2,4-D, only the $C$ types were produced. Treatment of anthers in darkness at $28^{\circ} \mathrm{C}$ during the first 14 days of the culture significantly increased the embryogenesis rate. Darkness at the beginning of the culture period seems to have a positive effect on the embryogenesis and callogenesis rate.

Ranunculus asiaticus / in vitro culture / anther / embryo

\section{INTRODUCTION}

Après une phase de recherches fondamentales sur quelques plantes modèles, la culture in vitro d'anthères apparaît comme une voie privilégiée d'haploïdisation (Maheshwari et al, 1982). Cette méthodologie est maintenant bien intégrée dans de nombreux programmes de sélection de plantes maraîchères et de grande culture (Doré, 1987). Elle est en revanche peu appliquée aux espèces ornementales car celles-ci sont, pour la plupart, cultivées à l'état de variétés-clones. Du fait de son mode habituel de multiplication par semences, la renoncule occupe une situation particulière qui justifie la recherche de lignées pures utilisables comme parents d'hybrides $F_{1}$. Or cette espèce est auto-incompatible (Meynet, 1985), et de telles lignées ne peuvent être obtenues que par haplodiploïdisation.

Par ailleurs, la culture d'anthères in vitro peut produire des embryons somatiques et éventuellement une variation somaclonale. Cette voie de recherche originale est actuellement développée chez la vigne par exemple (Mauro et al, 1985). Elle trouverait des applications immédiates pour la diffusion et la diversification éventuelle de nos variétés hybrides de clones.

La culture in vitro d'anthères a déjà permis d'obtenir des plantes entières viables d'origine pollinique chez plusieurs espèces de renoncula-

\footnotetext{
* Correspondance el tirés à part
} 
cées : Anemone virginia (Johansson, Eriksson, 1977), 5 autres espèces du genre Anemone et 4 espèces de Clematis (Johansson et al, 1982), plusieurs espèces du genre Paeonia (Sunderland et al, 1975).

\section{MATÉRIEL ET MÉTHODES}

Quatre clones consanguins ( 2 à 5 générations de croisements frère $x$ scur) et 4 hybrides de clones ont servi aux expérimentations. La liste est présentée dans le tableau $I$ avec leurs caractéristiques de fleurs (couleur et nombre d'étamines).

Les racines tubérisées (griffes) ont été implantées mi-octobre dans une serre dont la température est maintenue au-dessus de $+4^{\circ} \mathrm{C}$. Les prélèvements se sont échelonnés du 15 février au 31 mars sur des plantes en début et en pleine floraison.

Les repères morphologiques permettant de caractériser les stades polliniques sont indiqués dans le tableau II. La taille du bouton est extrêmement variable et ne peut être retenue comme indicateur d'un stade de la microsporogenèse. Les premières fleurs terminales sont souvent très grosses, très doubles et, par conséquent, déficientes en étamines, par suite d'une transformation pétaloïde des étamines. Nous avons donc prélevé de préférence les anthères sur le premier bouton axillaire, la fleur apicale servant alors de référence.

Tableau I. Couleur et nombre d'étamines du matériel utilisé.

\begin{tabular}{llr}
\hline Génotypes & $\begin{array}{l}\text { Couleur } \\
\text { de fleur }\end{array}$ & $\begin{array}{c}\text { Nombre } \\
\text { d'étamines }\end{array}$ \\
\hline S7002-6 & jaune bordé rouge & $45 \pm 8$ \\
S118-4 & $\begin{array}{l}\text { rose } \\
\text { rose }\end{array} 118-28$ & $65 \pm 10$ \\
S5145-24 & orange & $63 \pm 10$ \\
H1095 = & blanc bordé rose & $50 \pm 13$ \\
R34 S S7002-6 & jaune bordé rouge & $63 \pm 18$ \\
$55459=$ & S7002-6 & \\
H4129= & carmin & $53 \pm 23$ \\
R9 $\times$ S118-28 & rouge foncé & $53 \pm 14$ \\
R3065 $=$ & & \\
\hline
\end{tabular}

Après désinfection des boutons floraux par immersion dans une solution d'hypochlorite de calcium à $15 \mathrm{~g}^{-1} \mathrm{l}^{-1}$ pendant 20 min puis 2 rinçages à l'eau distillée stérile, on retire les sépales et pétales à l'aide d'un scalpel. Les anthères au stade "microspore uninucléée" sont prélevées et déposées à la surface d'un milieu gélosé à raison de 16 anthères par boîte de Petri de $55 \mathrm{~mm}$ de diamètre.

Les conditions culturales sont, selon les essais : $+4^{\circ} \mathrm{O}=$ réfrigérateur à $+4^{\circ} \mathrm{C}$ et obscurité $+18^{\circ} \mathrm{L}=$ chambre de culture réglée à $18^{\circ} \mathrm{C}$ éclairée pendant $12 \mathrm{~h}$ (tubes fluorescents fournissant environ $\left.12 \mathrm{~W} \cdot \mathrm{m}^{-2}\right)$

$+18^{\circ} \mathrm{O}=$ chambre de culture réglée à $18^{\circ} \mathrm{C}$ et obscurité

$+28^{\circ} \mathrm{O}=$ étuve à $+28^{\circ} \mathrm{C}$ et obscurité

\section{Les essais}

\section{Prétraitement des boutons par le froid}

Les boutons sont maintenus pendant $7 \mathrm{j}$ à $+4^{\circ} \mathrm{C}(\mathrm{F}+)$ ou ne subissent pas de froid $(\mathrm{F}-)$ avant d'être disséqués. Les anthères sont déposées sur un milieu de culture unique dépourvu d'auxine et contenant $1 \mathrm{mg} \cdot{ }^{-1}$ de $\mathrm{N}_{6}$-Benzyladénine, puis placées à $+18^{\circ} \mathrm{L}$. Quatre essais ont été successivement réalisés, les 17 et 26 février 1987 et les 7 et 23 mars 1988 avec 3 génotypes non apparentés : S7002-6, S118-28, et H3059.

\section{Traitement thermique des anthères en culture}

Les anthères mises en culture sur le même milieu que précédemment séjournent à $+4^{\circ} \mathrm{C},+18^{\circ} \mathrm{C}$ ou $+28^{\circ} \mathrm{C}$ à l'obscurité, pendant 1 ou $14 \mathrm{j}$, avant d'être toutes placées à $+18^{\circ} \mathrm{L}$ jusqu'à l'apparition de formations organogènes.

\section{Milieux de culture}

Tous les milieux expérimentés avaient en commun une composition de base comprenant : macroéléments de Murashige et Skoog dilués de moitié, microéléments de Skoog, et, pour 1 litre de solution, Fe EDTA: $65 \mathrm{mg}$, myo-inositol : $100 \mathrm{mg}$, acide nicotinique : $5 \mathrm{mg}$, pantothénate de calcium : $2 \mathrm{mg}$, thiamine $\mathrm{HCl}: 1 \mathrm{mg}$, pyridoxine $\mathrm{HCl}: 1 \mathrm{mg}$, glutamine : $100 \mathrm{mg}$, glycocolle : $100 \mathrm{mg}$, saccharose : $20 \mathrm{~g}$, agar : $8 \mathrm{~g}$.

Des essais ont été réalisés durant 3 années consécutives. Les essais du 20 février 1987 et du 9 mars

Tableau II. Repères morphologiques du stade d'évolution de la microsporogenèse dans le premier bouton axillaire prélevé. (1) Synthèse anthocyanique dans les anthères et filets staminiques des génotypes colorés : $-=$ nulle, $+=$ faible, $+++=$ forte ; (2) Axe longitudinal de l'anthère.

\begin{tabular}{llclll}
\hline Stade & Sac pollinique & Anthocyane (1) & Connectif & Axe L (2) & Bouton apical \\
\hline méiose & blanc hyalin & - & bien visible & droit & serré \\
tétrade & blanchâtre & - & visible & droit & fermé \\
uninuclée & jaunâtre & + & recouvert & courbé & couleur apparente \\
mature & jaune & +++ & caché & falciforme & épanoui \\
\hline
\end{tabular}


1988 portent sur la comparaison de 3 cytokinines: 2 doses de $\mathrm{N}_{6}$ Benzyladénine (BA), 2 doses de $\mathrm{N}_{6}$ (2isopentényl) adénine (2ip) et 2 doses de kinétine (K). Aucune auxine n'est ajoutée au milieu de culture. Les boutons floraux sont prétraités au froid et les anthères sont immédiatement placées à $+18^{\circ} \mathrm{L}$ après ensemencement. L'essai du 24 mars 1989 permet de comparer 2 milieux, l'un contenant $1 \mathrm{mg} . .^{-1}$ de BA et l'autre $0,5 \mathrm{mg} \cdot .^{-1}$ de BA et $0,1 \mathrm{mg} . \mathrm{l}^{-1}$ de 2,4-D. Après leur prélèvement, les anthères sont placées pendant 2 semaines à $+28^{\circ} \mathrm{O}$ puis 4 semaines à $+18^{\circ} \mathrm{O}$ et enfin à $18^{\circ} \mathrm{L}$.

\section{Remarques}

- Dans tous les essais les anthères sont maintenues sans repiquage sur leur milieu initial pendant toute la phase d'incubation, elles sont transférées sur un milieu de base contenant $0,5 \mathrm{mg} .1^{-1}$ de $B A$ et $0,5 \mathrm{mg} .1^{-1} \mathrm{~d}$ acide indole acétique (AIA) au fur et à mesure qu'apparaissent les formations organogènes.

- Les contaminations bactériennes sont très fréquentes et variables avec les donneurs (de $15 \%$ pour des plantes de semis à $60 \%$ et plus pour des clones parentaux multipliés par éclats de griffes depuis longtemps). Ces contaminations condamnent l'emploi de milieux de culture liquides ou la technique du double lit (phase liquide au-dessus d'un milieu gélosé contenant du charbon actif) préconisée par Johansson et al (1982).

\section{RÉSULTATS}

Les anthères de renoncule mises en culture développent 2 types bien distincts de formations organogènes :

\section{Apparition d'embryons somatiques à la sur- face de l'anthère}

Six à 12 semaines après la mise en culture (avec un maximum à la $10^{\circ}$ semaine) des embryons blancs apparaissent sur la surface de l'anthère qui est restée bien fermée, très rarement à la surface du connectif ou du filet staminique. La durée de l'évolution du stade globulaire au stade cordiforme n'excède pas 2 semaines. Ces embryons proviennent des tissus superficiels, probablement de l'épiderme, de l'anthère non déhiscente et sont donc d'origine somatique, ils seront notés "Em" par la suite.

\section{Apparition de cals issus de l'intérieur de l'an- thère}

Après 10 à 18 semaines (avec un maximum à 13 semaines) des nodules et des cals globulaires denses sortent de l'intérieur de l'anthère par la fente de déhiscence, ils seront notés " $\mathrm{C}$ ".
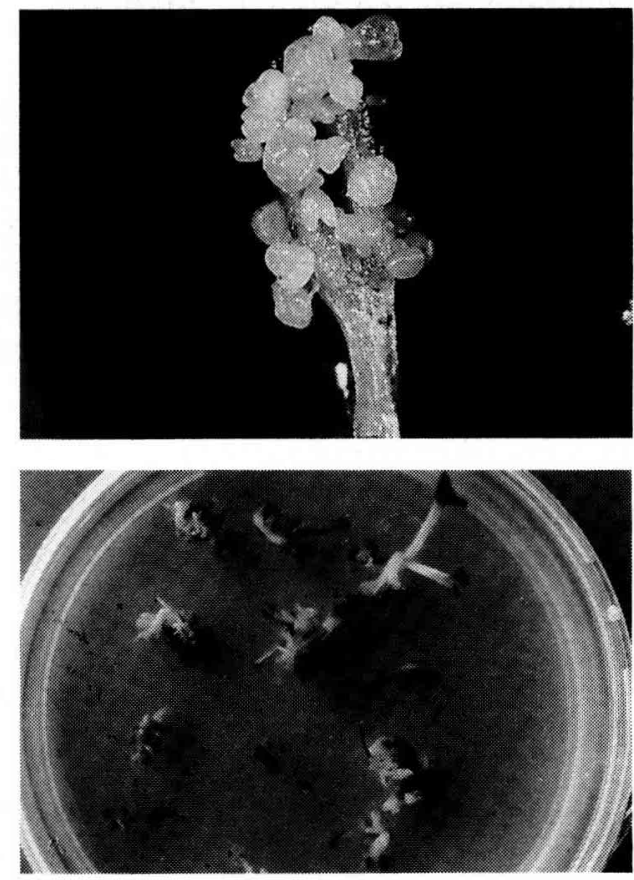

Fig 1. Embryons somatiques Em à la surface d'une anthère indéhiscente. a : 10 semaines après mise en culture $(x 10)$; $b$ : 16 semaines après mise en culture $(x 2)$.

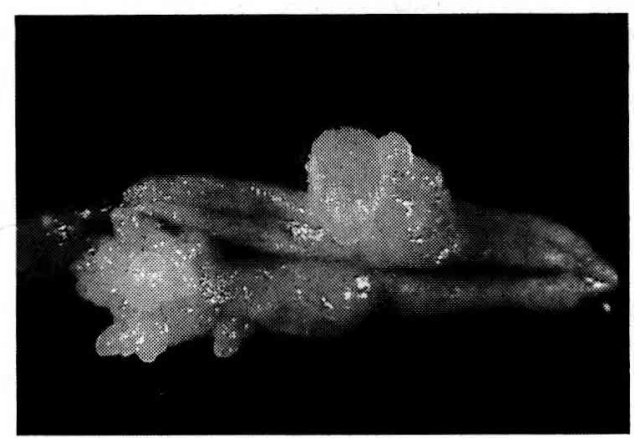

Fig 2. Cals $\mathrm{C}$ sortant de la fente de déhiscence 13 semaines après la mise en culture ( $x 15)$.

Ces 2 types de formations ont donné, par évolution embryogénétique directe ou par régénération de cals, des plantes entières cultivables en serre avec un pourcentage de survie de $60 \%$ des embryons $\mathrm{Em}$ et de $45 \%$ des cals C.

L'origine somatique des plantes Em sera discutée et confirmée dans un prochain article (Meynet, Duclos, 1990). Quant aux plantes C, leur très faible vigueur a beaucoup gêné leur analyse génétique : les dénombrements chromosomiques sur pointes de racines ont révélé 3 plantes haploïdes $(n=8)$ et 5 diploïdes, leurs premières descendances sexuées sont en cours d'observation. Il est probable que les plantes $C$ diploïdes proviennent d'un doublement spontané mais aujourd'hui on ne peut pas exclure la possibilité de régénération de quelques plantes à partir de cals provenant des parois somatiques de l'anthère. 


\section{Prétraitement des boutons par le froid}

L'effet des dates d'essais n'étant pas significatif, nous avons regroupé les résultats par génotype donneur tableau III. Malgré la faiblesse des effectifs et la grande variation des réponses à l'intérieur d'un même traitement, un effet positif du froid sur le nombre d'anthères réactives $\left(\chi_{1}^{2}=7,1\right)$ et le nombre d'embryons obtenus $\left(\chi_{1}^{2}=10,9\right)$ peut être observé globalement.

\section{Traitement thermique des anthères en culture}

Les tableaux IVa et IVb indiquent que, seul un passage des anthères à $28^{\circ} \mathrm{C}$ pendant $14 \mathrm{j}$ aug- mente de façon très significative la fréquence des anthères réactives $\left(\chi_{1}^{2}=72,28\right)$, des embryons $\operatorname{Em}\left(\chi_{1}^{2}=96,08\right)$ et probablement des nodules et cals $C$, les autres traitements testés, en particulier le froid, restant sans effet.

\section{Milieux de culture}

Dans nos conditions expérimentales, les résultats de 1987 et 1988 sont convergents et ont été regroupés dans le tableau $V$, les 2 doses de 2ip et de $\mathrm{K}$ donnent des résultats comparables, seule la BA marque une différence significative par rapport au témoin sans substance de croissance $\left(\chi_{1}^{2}=23,81\right)$, la dose de $0,1 \mathrm{mg} \cdot .^{-1}$ est ici légèrement plus inductrice que celle de $1 \mathrm{mg}^{-1} \mathrm{l}^{-1}$ $\left(\chi_{1}^{2}=7,66\right)$.

Tableau III. Effet d'un prétraitement des boutons floraux par le froid sur le nombre d'embryons Em ou de cals $C$ produits. $M C=$ nombre d'anthères mises en culture ; $A s=$ nombre d'anthères saines ; $A r=$ nombre d'anthères ayant donné au moins une formation morphogène $; E m=$ nombre d'embryons $; C=$ nombre de nodules et de cals ; \% $=$ $(\mathrm{Em}+\mathrm{C}) / 100$ As.

\begin{tabular}{lrrrrrrrrrrrrr}
\hline & \multicolumn{1}{c}{$F+$} & \multicolumn{1}{c}{$F-$} \\
\hline Donneur & MC & As & Ar & Em & C & $\%$ & MC & As & Ar & Em & C & $\%$ \\
S7002-6 & 400 & 162 & 7 & 25 & 3 & 17,3 & 400 & 125 & 2 & 5 & 0 & 3,7 \\
S118-4 & 400 & 278 & 4 & 0 & 5 & 1,8 & 400 & 297 & 1 & 0 & 3 & 1,0 \\
H3059 & 688 & 497 & 15 & 25 & 0 & 5,0 & 688 & 491 & 7 & 17 & 0 & 3,5 \\
Total & 1488 & 937 & 26 & 50 & 8 & 6,2 & 1488 & 923 & 10 & 22 & 3 & 2,7 \\
\hline
\end{tabular}

Tableau IV. Effet de différentes températures au début de la culture in vitro des anthères sur la production d'embryons et de cals.

IVa : Essai du 20 février $87:$ Les 14 premiers jours de culture se déroulent à l'obscurité soit à $+18^{\circ} \mathrm{C}$ soit à $+28^{\circ} \mathrm{C}$.

\begin{tabular}{lrrrrrr}
\hline Donneur & \multicolumn{3}{c}{$H 3059$} & \multicolumn{2}{c}{ H4129 } & \multicolumn{2}{c}{ Total } \\
\hline température & $18^{\circ} \mathrm{C}$ & $28^{\circ} \mathrm{C}$ & $18^{\circ} \mathrm{C}$ & $28^{\circ} \mathrm{C}$ & $18^{\circ} \mathrm{C}$ & $28^{\circ} \mathrm{C}$ \\
MC & 240 & 240 & 240 & 240 & 480 & 480 \\
As & 206 & 195 & 180 & 192 & 386 & 387 \\
Ar & 5 & 18 & 2 & 5 & 7 & 23 \\
Em & 12 & 33 & 0 & 0 & 12 & 33 \\
C & 0 & 0 & 2 & 8 & 2 & 8 \\
$\%$ & 5,8 & 16,9 & 1,1 & 4,2 & 3,6 & 10,6 \\
\hline
\end{tabular}

IVb : Essais du 17 février et du 14 mars 88 . * $A=S 7002-6 ; B=S 118-4$.

\section{Conditions}

de température

et d'éclairement

$+4^{\circ} \mathrm{O}+18^{\circ} \mathrm{O}$

$+28^{\circ} \mathrm{O}$

$\begin{array}{lllllll}\text { Durée (jours) } & 1 & 14 & 1 & 14 & 1 & 14\end{array}$

\begin{tabular}{|c|c|c|c|c|c|c|c|c|c|c|c|c|}
\hline Donneur & $A^{*}$ & $B^{*}$ & $A$ & $\mathrm{~B}$ & A & B & A & $\mathrm{B}$ & $A$ & $\mathrm{~B}$ & A & $B$ \\
\hline$M C$ & 240 & 240 & 240 & 240 & 240 & 240 & 240 & 240 & 240 & 240 & 240 & 240 \\
\hline As & 115 & 196 & 107 & 205 & 112 & 191 & 895 & 197 & 106 & 200 & 84 & 118 \\
\hline $\mathrm{Ar}$ & 3 & 0 & 2 & 1 & 3 & 1 & 2 & 1 & 3 & 1 & 10 & 5 \\
\hline Em & 5 & 0 & 3 & 0 & 3 & 0 & 3 & 0 & 6 & 0 & 24 & 0 \\
\hline C & 0 & 0 & 0 & 1 & 0 & 1 & 0 & 1 & 0 & 1 & 0 & 11 \\
\hline$\%$ & 4,3 & 0 & 2,8 & 0,5 & 2,7 & 0,5 & 3,2 & 0,5 & 5,7 & 0,5 & 28,6 & 5,9 \\
\hline
\end{tabular}


Dans l'essai de 1989 dont les résultats sont rapportés tableau VI les anthères des meilleurs donneurs ont été placées dans les conditions physiques optimales $\left(14 \mathrm{j}\right.$ à $\left.+28^{\circ} \mathrm{O}\right)$; les taux de production sont alors très élevés. Les effets des 2 milieux comparés varient avec le génotype du donneur:

- avec S118-28, H3065 et H4129 : aucune influence des milieux n'est décelable.

- avec H1095 : le milieu ne contenant que de la $B A$ induit uniquement des nodules et cals $C$ provenant de l'intérieur de l'anthère, alors que le milieu contenant à la fois de la BA et du 2,4-D permet, dans un premier temps, l'apparition d'un très grand nombre d'embryons $E m$ puis, 2 à 4 semaines plus tard, des nodules $C$. Pour la première fois nous avons observé sur ce dernier milieu enrichi en 2,4-D des anthères capables de donner à la fois les 2 types de formations $\mathrm{Em}$ et C (fig 3).

\section{DISCUSSION ET CONCLUSION}

Chez la renoncule, la culture in vitro d'anthères produit 2 types bien distincts de formations organogènes : les types $\mathrm{Em}$ d'origine somatique exclusivement, les types $C$ en majorité d'origine gamétique.

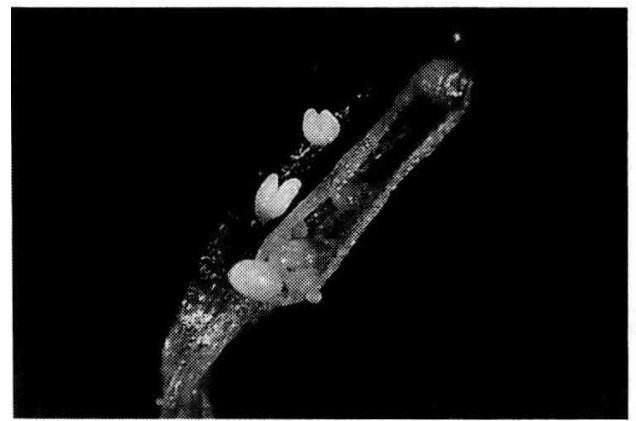

Fig 3. Anthère présentant les 2 types Em et $\mathrm{C}$ de formation embryogénétique après 12 semaines de culture in vitro (x 10).

Jusqu'à présent le génotype du donneur prédétermine de façon quasi systématique l'origine tissulaire de l'explant produit ; une exception peut être notée avec le donneur $\mathrm{H} 1095$ qui exige du 2,4-D pour donner des types $\mathrm{Em}$ mais qui peut produire des types $C$ aussi bien en présence qu'en absence de 2,4-D. A notre connaissance une situation aussi nettement tranchée n'a jamais été décrite. La renoncule, par ses aptitudes morphogénétiques spécifiques, paraît être un matériel de choix pour l'étude des processus d'initiation de la morphogenèse.

L'effet positif d'un prétraitement des boutons floraux par le froid a déjà été mentionné, en particulier chez plusieurs espèces d'anémones

Tableau V. Influence des cytokinines contenues dans le milieu de culture sur le nombre d'embryons Em et de cals $C$ produits sur les anthères de 3 génotypes (résultats cumulés des essais de 1987 et 1989).

\begin{tabular}{|c|c|c|c|c|c|c|c|c|c|c|c|c|}
\hline \multirow{2}{*}{$\begin{array}{l}\text { Donneur } \\
\text { Cytokinine mg. } .^{-}\end{array}$} & \multicolumn{4}{|c|}{ S5145 } & \multicolumn{4}{|c|}{ H3059 } & \multicolumn{4}{|c|}{ S118-10 } \\
\hline & As & $E m$ & C & $E m(\%)$ & As & $E m$ & $C$ & $E m(\%)$ & As & $E m$ & c & $C(\%)$ \\
\hline 0 & 95 & 0 & 0 & 0 & 440 & 14 & 0 & 3,2 & 379 & 0 & 0 & 0 \\
\hline BA 0,1 & & & & & 288 & 40 & 0 & 13.9 & 345 & 0 & 5 & 1,5 \\
\hline $\mathrm{BA} 1$ & 155 & 2 & 0 & 1,3 & 318 & 36 & 0 & 11,3 & 356 & 0 & 6 & 1,7 \\
\hline 2 ip 0,1 & & & & & 239 & 9 & 0 & 3,8 & 363 & 0 & 0 & 0 \\
\hline 2 ip 1 & 123 & 2 & 0 & 1.6 & 254 & 12 & 0 & 4.7 & 336 & 0 & 0 & 0 \\
\hline$K 0,1$ & & & & & 286 & 11 & 0 & 3,8 & 375 & 0 & 3 & 0,8 \\
\hline $\mathrm{K} 1$ & & & & & 330 & 22 & 0 & 6,7 & 353 & 0 & 2 & 0,6 \\
\hline
\end{tabular}

Tableau VI. Effet de 2 milieux de culture distincts par leurs régulateurs de croissance, l'un contient $1 \mathrm{mg} . .^{-1} \mathrm{de}$ BA l'autre $0,5 \mathrm{mg.} \mathrm{l}^{-1}$ de $B A$ et $0,1 \mathrm{mg} . \mathrm{l}^{-1}$ de $2,4-\mathrm{D}$, sur le nombre d'anthères morphogènes et le taux d'embryons ou de cals produits par 100 anthères cultivées selon les génotypes donneurs (essai 1989).

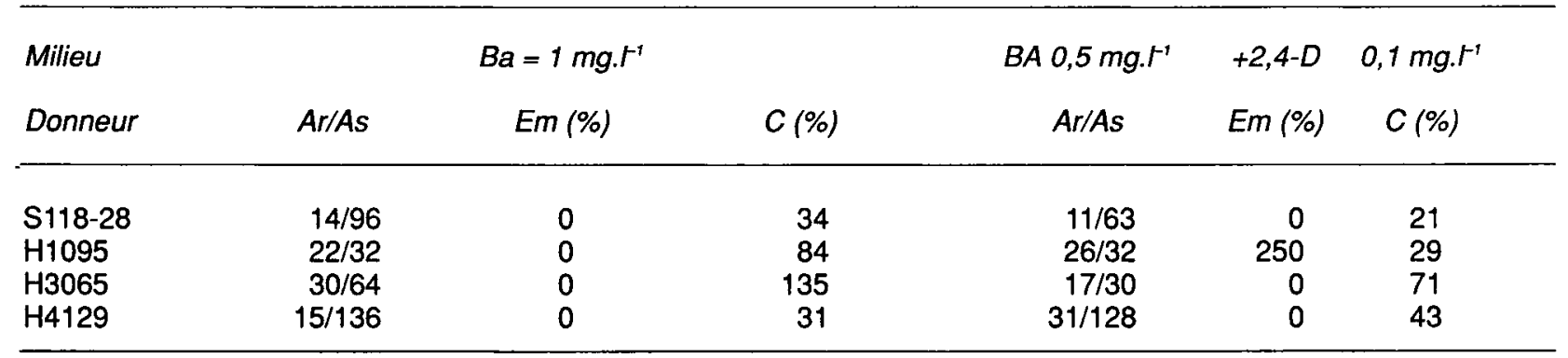


(Johansson, Eriksson, 1984) ; il est ici très limité et ne paraît pas déterminant.

En revanche, un passage des anthères dès le début de la culture pendant $14 \mathrm{j}$ à $+28^{\circ} \mathrm{C}$ (température très élevée par rapport à l'optimum thermique de croissance de $18^{\circ} \mathrm{C}$ environ) stimule très fortement la production de plantes pour tous les donneurs testés.

L'action positive de températures élevées en début de culture a souvent été décrite (Dumas de Vaulx et al, 1981 ; Dumas de Vaulx, Chambonnet, 1982 ; Maheshwari et al, 1982, par exemple). Chez Anemone virginia, Johansson, Eriksson (1977) observent que la température optimale pour la production d'embryons est de $25^{\circ} \mathrm{C}$ (bien au-dessus de la température de croissance), mais surtout, que l'obscurité est nécessaire pour avoir des taux d'embryogenèse élevés : chez $R$ asiaticus, l'effet favorable de l'obscurité n'est pas formellement démontré ; à $18^{\circ} \mathrm{C}$ (tableau IVb) aucune différence n'apparaît après 1 ou $14 \mathrm{j}$ à l'obscurité, mais la durée du traitement est peut-être trop courte. En revanche, si les anthères du génotype $\mathrm{H} 4129$ sont maintenues pendant 6 semaines à l'obscurité, le taux de formations $\mathrm{C}$ obtenues par rapport au nombre d'anthères en culture atteint $31 \%$ (essai de 1989 , tableau VI) alors qu'il n'était que de $4,2 \%$ après 2 semaines à l'obscurité (essai de 1987, tableau IVa), toutes les autres conditions restant égales par ailleurs. Cette différence considérable suggère un effet positif important de l'obscurité en début de culture, pourvu qu'elle agisse pendant une durée suffisante supérieure à 2 semaines.

Le rôle des milieux de culture, et notamment des équilibres hormonaux, est loin d'être entièrement élucidé. Des plantes ont pu être obtenues sur de nombreux milieux très différents et en particulier sans aucune substance de croissance. Les résultats reportés ici indiquent un effet globalement favorable de la BA sur la fréquence d'émergence aussi bien des types Em que $\mathrm{C}$ alors que le 2,4-D favoriserait chez certains génotypes la production d'embryons Em (peutêtre au détriment des types $C$ ).

\section{REMERCIEMENTS}

Nous remercions $F$ Pecate qui a participé à ce travail dans le cadre de la préparation de son mémoire de fin d'études de l'Ecole Nationale Supérieure Agronomique de Toulouse au cours de son stage du $1^{\text {er }}$ février au 25 août 1988.

\section{RÉFÉRENCES}

Doré C (1987) Intégration de la culture in vitro dans les méthodes de sélection de plusieurs espèces potagères. Thèse de doctorat d'Etat, Univ Paris-Sud Orsay, $301 p$

Dumas De Vaulx R, Chambonnet D, Pochard E (1981) Culture in vitro d'anthères de piment (Capsicum annuum) : Amélioration des taux d'obtention de plantes chez différents génotypes par des traitements à $35^{\circ} \mathrm{C}$. Agronomie 1, 859-864

Dumas De Vaulx R, Chambonnet D (1982) Culture in vitro d'anthères d'aubergine (Solanum melongena L) : stimulation de la production de plantes au moyen de traitements à $35^{\circ} \mathrm{C}$ associé à de faibles teneurs en substances de croissance. Agronomie 2, 982-988

Johansson L, Eriksson T (1977) Induced embryo formation in anther cultures of several Anemone species. Physiol Plant 40, 172-174

Johansson L, Eriksson T (1984) Effects of carbon dioxide in anther culture. Physiol Plant 60, 26-30

Johansson L, Andersson B, Eriksson T (1982) Improvement of anther culture technique. Activated charcoal bound in agar medium in combination with liquid medium and elevated $\mathrm{CO}_{2}$ concentration. Physiol Plant 54, 24-30

Maheshwari SC, Rashid A, Tyagi AK (1982) Haploïds from pollen grains. Retrospect and prospect. $A m$ J Bot 69, 865-879

Mauro $\mathrm{MCl}$, Nef C, Ambid C, Fallot J (1985) Utilisation de l'embryogenèse somatique en vue d'augmenter la variabilité chez Vitis vinifera var Carbernet-Sauvignon. Atti symposia di genetica della viti, Verona, $27-29$

Meynet $J(1985)$ Multiplication et sélection de la renoncule. PHM Rev Hortic 254, 55-62

Meynet J, Duclos A (1990) Culture in vitro de la renoncule de fleuristes (Ranunculus asiaticus). III. Etude des plantes produites par embryogenèse somatique à partir de tissus superficiels de l'anthère. Agronomie 10 (accepté pour publication)

Sunderland N, Dunwell JM, Roberts M (1975) Anther culture in the genus Paeonia. Ann Rep John Innes Inst 66, 57-60 